volatile matter in passing from east to west, and a corresponding decrease in the nystagmus. In the meantime we feel that it would be a mistake to disregard the recommendation of the Miners' Nystagmus Committee, namely, to improve the illuminating conditions under which the miners work.

\title{
ABSTRACTS
}

\section{I.-CARCINOMA OF THE CHOROID}

Greenwood, Allen (Boston, Mass.).-Carcinoma of the choroid. Internat. Congress of Ophthal., April, 1922.

The salient facts of the four cases of carcinoma of the choroid reported by Greenwood were as under: 1. A man came on account of acute glaucoma of one eye. The fundus of that eye, after the glaucoma had been relieved by miotics, showed in one part a separation of the retina, covering a flat, greyish-white mass. The liver was enlarged, and as it seemed doubtful if the case was one of sarcoma or carcinoma, the eye was not removed. Prior to death, the brain became involved. At the autopsy the primary source of the general carcinomatosis was found to be the prostate. The organs more particularly involved were the lungs, pleura, peribronchial glands, liver, brain, and eye. In this case the eye condition was the first to call attention to the possibility of disease in other parts of the body. 2. A woman of 48 complained of one eye, the sight of which was reduced to hand movements in the outer field. Retinal separation was found, through which could be seen a white mass raised towards its central part about 3D. and flattening out in all directions. It is compared by the author to some substance such as cheese inserted under the retina. Patient found to be affected with cancer of the breast, involving lung and axillary glands. Some four months later carcinoma found in the other eye. Death from cerebral involvement. 3. Woman, aged 60 years, vision failing in both eyes for several months. Two years previously breast amputated and axilla cleared of carcinomatous glands. Detachment of retina, with underlying greyish mass, in each eye. Patient died with cerebral symptoms. 4. Woman, aged 36 years, R.V. 20/30 a very flat, round, white, discoid subretinal mass found down and out from macula of R.E. History of operation about a year previously for mammary cancer. $\mathrm{X}$-ray examination showed extensive involvement of one lung. 
Examination of Greenwood's four cases discloses some facts worthy of notice. In all, X-rays, autopsy, or physical signs showed that the lungs were involved. In fact, the finding of a whitish, discoid, subretinal tumour, without reaction or independent vascular system, should lead to careful examination of the lungs. Pain and increased intraocular pressure are the only complications that call for removal of the eye, although a doubt as to the growth being a sarcoma would justify it. Carcinoma is usually seated posteriorly, projects but little to the vitreous, spreads rapidly, but remains flat. Vision is soon lost. Tension is not usually disturbed in the early stage. The tumour is always metastatic and the primary focus can generally be found. Treatment is palliative and prognosis inevitably bad.

S. S.

\section{II.-REMEDIES}

(I) Moore, R. Foster (London).-A case of cure of detachment of retina. Lancet, July 23, 1921.

(1) Foster Moore publishes, with diffidence and much restraint, what appears to be a cure of a case of retinal detachment by a method he has been in the habit of employing. It is a myopic case with " a large transparent retinal detachment down and out." The routine treatment referred to is as follows :-Confinement to bed; injections of 5 per cent. sodium chloride and 5 per cent. sodium citrate solutions, with the addition in each case of 4 per cent. novocain, in amounts of about 15 minims, under Tenon's capsule over the site of the detachment. The injections of these two solutions are made alternately every three days. Nine or ten injections in all. After the treatment in this case five of Foster Moore's colleagues failed to find any evidence of detachment. The Editor of the Lancet, making the case the text for a note on retinal detachment and the difficulty of its treatment, points out that the retina has not been re-attached for a sufficiently long period (a few weeks) to warrant the word " cure." . ERnest Thomson.

(2) Virgilli, Rovirosa (Madrid).- Treatment of infective keratitis by vaccines. (Tratamientos de las queratitis infeccioasas por las vacunas.) Internat. Congress of Ophthal., Washington, D.C., April, 1922.

(2) Virgilli reports results secured in the treatment of ocular disease with vaccines, more especially with the staphylococcus 
vaccine in suppurative keratitis. In all the cases of keratitis treated in that way were observed rapid cicatrization, absence of scarring, and in most of the cases preservation of function. Vaccines, therefore, deserve to occupy the first place in the treatment of ulcerative keratitis. Virgilli prefers the polyvalent stock vaccines, but in the event of their being inefficient auto-vaccines may be employed. When in place of sera, vaccines are used toxins are injected compelling a reaction on the part of the organism, which produces antibodies that destroy the germs and neutralize their toxins. Cases of panophthalmitis are cited in which enucleation had been recommended, but which retained the eye under vaccine treatment. All cases of marginal blepharitis were benefited, mostly by staphylococcus vaccine, but in one instance by an auto-vaccine containing streptococcus.

S S.

(3) Davis, A. Edward (New York City).-Serum and vaccine treatment for the prevention and cure of cataract. Internat. Congress of Ophthal., Washington, D.C., April, 1922.

(3) The special sera and vaccines used in Davis's experiments were cytolytic in nature, that is, they were secured by injecting the crystalline lens tissue of one species into another, producing a lytic substance (a cytolysin) in the blood of the latter. The sera from the blood of the injected species when reinjected into the species furnishing the antigen have a dissolving or lytic effect on the special tissue used as antigen-the crystalline lens in these experiments. In other words, they act similarly to the haemolysins; in fact according to Guyer and Smith, all haemolytic sera so far studied have been found to be more or less haemolytic in action. Like the haemolysins, they are also specific in action on the special tissue used as the antigen in the sensitizing process. However, they are not absolutely specific, as homologous tissues may be affected to a slight extent, e.g., the vitreous, when lens is used as antigen. According to Ehrlich and his school, the lack of absolute specificity is due to the fact that more or less homologous tissues may have common receptors.

Davis concludes as follows: " The crystalline lens, like uveal pigment, is organ-specific and not species-specific; and according to Hektoen, lens protein may be regarded as chemically distinct and as identical in diverse species. In the first experiments only anti-human rabbit cytolysins were used, but later other lens proteins were used in preparing the cytolysins.

The antigen in all these cases was given intravenously in preparing these sera; also the sera and vaccines were administered 
to the patients intravenously, at about five-day intervals. Intradermal tests were made on the patients from time to time to test the sensitiveness of the patients to the treatments." S.S.

\section{III.-BLACK CATARACT}

Rollet, Prof. (Lyons) and Bussy, Dr.-Black cataract. (La cataracte noires.) Arch. d'Ophtal., Feb., 1921.

Rollet and Bussy have taken the opportunity of an unfortunate experience with a black cataract to write an interesting little monograph on the subject. Their patient was a man of 60 , who had had a black cataract operated on by Dor ten years previously. This operation was followed by severe inflammation, which had left only a sightless stump which was very hard and contained bone. The other eye had slowly developed a complete black cataract. In view of the bad results following the first operation extra precautions were taken before operating on the left eye. These included the removal of the right stump and careful treatment of the conjunctiva and lacrimal apparatus. The operation was quite straightforward, and was made with an iridectomy and a large flap. All went well for a week, and then cyclitis set in, and three months later the eye was soft and vision was only quantitative with uncertain projection.

The paper then gives a most interesting account of the history of black cataract going back to Maître-Jan in 1707. The difficulty of diagnosis without an ophthalmoscope led most surgeons, to disbelieve in its existence altogether, and even, horribile dictu (but, of course, this was a long time ago), to suggest that it was merely a method of extracting money from the pockets of the unfortunate victims by operating on clear lenses.

The authors obtained three lenses and used one half of each for histological examination, and the other half for chemical analysis. They sum up the results as follows :-

"Black cataract is the final term of a series which includes all senile cataracts from the clear yellow ones to those that are absolutely black. A deep tint is not sufficient by itself to determine this clinical and anatomical individuality; it is necessary that the tint should affect also the cortical layers, and that the whole lens should be black. In this case only has the variety a real clinical existence and presents some difficulty in diagnosis. It must not be confused with certain dystrophic cataracts, secondary to traumatism or intraocular haemorrhage. It affects elderly subjects and develops very slowly. The prognosis of operation is not so good as in the ordinary variety. It is characterized by densification of the lens fibres which resemble serrated 
fibres, and show neither granulations nor globules, nor destructive process, nor pigment of any sort. The dark tint of black cataract is due to the presence of oxidised tyrosin in the interior of the lens."

A comprehensive bibliography accompanies the paper.

E. E. H.

\section{IV.-PSEUDOBLASTOMA OF THE ORBIT}

Mairbaix, Dr. (Tournai) and van Duyse, Prof. D. (Ghent).Pseudoblastoma of the orbit. Pseudoleukaemic lymphomatosis (lymphocythaemic). (Lymphomatose pseudoleucémique (lymphocytémique). Arch. d'Ophtal., August, 1921.

Marbaix and van Duyse record a case of orbital tumour in a girl of eleven. When first seen the patient had slight ptosis on the right side and almost complete limitation of movement of the globe except outwards. The globe was pushed outwards and forwards, but could be pushed back readily without pain and was quite moveable under pressure. There was paralysis of accommodation and of the pupil, but distant vision was not interfered with. As the proptosis got more marked and was accompanied by pain it was decided to expose the orbit by a Krönlein's operation. At this operation the lacrimal portion of the orbital gland was removed. A fortnight later the cornea, which was quite insensitive, showed some opacity. This post-operative paralytic keratitis cleared up and vision remained normal. There was at no time any evidence of implication of the optic nerve. No definite tumour mass could be made out at the time of operation with the exception of the enlarged lacrimal gland. The microscopical examination of this structure gave the explanation of the condition. This showed foci of perivascular lymphocytes with hyaline degeneration of the interstitial connective tissue and vessel walls. Blood tests gave an excess of lymphocytes with a slight diminution of red blood corpuscles and indicated a condition of pseudoleukaemia.

The authors discuss the views of other writers, more particularly those of Birch-Hirschfeld, and conclude as follows :-

"The chronic inflammatory lymphomatosis frequently described in the orbit may be the expression of a general affection of a not very obvious type and connected with lymphocythaemia.

Among the methods in clinical use for the diagnosis of orbital tumours the quantitative determination of the haematological formula must not be omitted. 
In a case of definite lymphocythaemia, the neoplasm being derived from the leucocythaemia, treatment by arsenic or radium should take the place of any operative interference."

Drawings of the microscopic appearances of the lacrimal gland and a bibliography accompany the paper.

E. E. H.

\section{V.-RECURRENT HYPERAEMIA OF THE EYELIDS}

\section{Weekers, L., and Halikin, H.-Paroxysmal recurrent hyperaemia} of the eyelids. (Hyperémie paroxystique récidivante des insensitive showed some opacity. This post-operative paralytic paupières.) Arch. d'Ophtal., Nov., 1921.

Weekers and Halikin under this heading describe a condition which they consider has not so far received attention. The case described was that of a boy of fifteen who had suffered from the age of eight from recurrent attacks of swelling, redness, tenderness and discoloration of the left eyelid. At first the recovery was complete and rapid, but gradually the lid became flabby and thick. When first seen by the authors he had had no attack for six months, and has had none since. Vision had never been affected, but on several occasions there had been bleeding from behind the upper lid. Examination showed marked ptosis with discoloration of the skin, which was wrinkled and roughened like shagreen. The conjunctiva of the upper lid was injected, as was also that of the upper part of the globe. This injection was much increased by the most gentle manipulation. The lower lid was perfectly normal. The general health and family history of the patient were excellent in every respect. A semilunar piece of skin was excised with excellent results from a cosmetic point of view. A careful microscopic examination of the piece removed showed the following principal changes :-

" 1. Vascular proliferation specially marked in the layers beneath the skin : subcutaneous, muscular and pretarsal tissue, with no indication of any inflammatory reaction.

2. Dilatation with moderate inflammatory reaction of the small vessels of the dermis, but chiefly localized oedematous displacement of the dermal tissue and dilatation of the lymphatic spaces.

3 . The almost complete disappearance of the elastic tissue.

4. Diminution of the epidermis."

The authors consider that the disease should be classed amongst the dermatoses and discuss the various allied skin affections previously described by dermatologists.

A photograph of the patient and also of the microscopic sections accompany the paper.

E. E. H. 


\section{VI.-MISCELLANEOUS}

(I) Vail, Derrick T. (Cincinnati).-Monocular retrobulbar optic neuritis from hyperplasia of the ethmoid bone. Report of three cases with operation. Amer. Jl. Ophthal., February, 1919.

(1) Vail defines hyperplasia as an increase of the connective tissue elements of living anatomic structures, due to a low grade of localized inflammation. It is a non-suppurative process taking the form of a rarefying osteitis associated with inflammatory swelling and fibrous thickening of the mucous membrane lining its cavities, causing oedematous tissue to fill them. The lining wall is also thickened and the entire organ is enlarged so that the orbital wall is involved as well as the nasal. Apart from ocular complications the symptoms are said to be trivial and the disease is common. The reason of the rarity of affection of the optic nerve is due to the anatomical arrangements of the posterior ethmoidal cells which only occasionally come into close contact with the optic canal. The author discusses at some length the symptomatology of retrobulbar neuritis, the only distinctive feature of the class of case he treats of being the fact that it is always uniocular. He admits that it may be impossible to recognize any disease of the ethmoid before operation. Careful radiography is of great assistance, oblique exposure of the ethmoid showing distinct cloudiness of posterior ethmoidal cells in two of his three illustrative cases.

Case I was a man of 35 years, who was a total abstainer from alcohol and tobacco. When first seen, twelve days after the vision of the right eye became misty, he was unable to count fingers with it, vision in the other eye was normal. There was a large absolute central scotoma. A fortnight after exenteration of the right ethmoidal labyrinth vision was $20 / 50$, and the scotoma was much smaller. One year later vision was $20 / 20$ and Jaeger 1 , but the disc was very white, especially on the temporal side.

Case II was a woman of 18 years, who had suffered two weeks previously from a cold in the head with conjunctivitis. The right eye was normal in every respect, but the left eye had only $20 / 200$, with a large absolute central scotoma. Details of fundus quite hazy owing to presence of a definite neuro-retinitis. Exenteration of left ethmoid showed pus in the cells, although previous rhinoscopic examination had been negative. A year later vision was $20 / 70$, and the disc atrophic, scotoma considerably smaller.

Case III. A woman of 60 years, who had completely lost the sight of the right eye three weeks previously. The vision of the left eye was normal ; there was no perception of light in the right. Nasal examination showed no abnormality. The right ethmoid was exenterated. Thirteen months later she could count fingers 
eccentrically, and the peripheral field was normal, but a large central scotoma remained. The disc was atrophic.

Vail considers that his cases illustrate two distinct types of affection due to the ethmoid; cases one and three being due to pressure producing a transverse neuritis, while case two being combined with neuro-retinitis shows the effect of a septic process in producing an interstitial neuritis.

We have all met with cases of uniocular and binocular retrobulbar neuritis which have recovered good vision, even after that has been reduced to mere perception of light, without any surgical interference. Some of these have turned out later to be the precursors of disease of the central nervous system. It seems a little heroic to submit patients to such an operation as exenteration of the ethmoid in the absence of any more direct evidence of the involvement of that structure than the presence of retrobulbar neuritis.

E. E. H.

(2) Sauvineau, $\mathrm{Ch}$. - The origin and the aetiological treatment of disease of the lacrimal passages. The importance of lacrimation due to hypersecretion. (Origine et traitement étiologique des maladies de voies lacrymales. Importance du larmoiement par hypersécrétion.) La Clin. Ophtal., January, 1920.

(2) Sauvineau tilts at the treatment of lacrimal obstruction by catheterisation, which treatment is founded, he says, on the supposition that stricture is the cause of the lacrimation and subsequent infection. He holds, on the contrary, that " in the immense majority of cases" lacrimation comes first, is due to hypersecretion, causes stagnation by overtaxing the channels, and is followed by infection and consequent stricture. The cause of the lacrimation is an error of refraction or of convergence. It follows that during the period of simple lacrimation probing is wrong. An injection of sterile water will show in these cases (the "immense majority" of cases as stated above) that the duct is patent and the obvious treatment is correction of the error of refraction or of convergence. Whether this argument is conclusive or not it is at any rate suggestive.

ERnest Thomson.

(3) Verderame, Philippe (Turin).-The visibility of the corneal nerves under pathological conditions. (Visibilité des nerfs cornéens à l'état pathologique.) Revue Générale d'Ophtal. December, 1920.

(3) Only a few observers have described the clinical appearance of the corneal nerves, and that mainly under normal conditions. The interest of Verderame's communication lies in the fact that in a 
case of intensely painful syphilitic irido-cyclitis the corneal nerves were observed by ordinary focal illumination, and disappeared from view when the inflammation passed off. The nerves appeared as delicate white threads, radially disposed, and much more visible at the periphery than towards the centre of the cornea. They were observed to branch dichotomously and sometimes trichotomously, thus forming a finer and finer arborisation. No trace of blood vessels was found even on high magnification. Verderame considers that the visibility of the nerves in this case resulted from a specific inflammation of the nerves and the neighbouring tissue, that is, a neuritis and perineuritis. As the inflammatory products were resorbed the extreme tenderness of the eye disappeared, and with it the visibility of the corneal nerves.

ERNEST ThOMSON.

(4) Duverger, M.-On the repair of the angles of the lids. (De la refection des angles des paupiéres.) Arch. d'Ophtal., Jan., 1921.

(4) Duverger in a previous paper, described his method of lid suture in two planes to obviate the formation of a coloboma (Arch. d'Ophtal., 1917). In the present paper he describes certain modifications necessary when the tear is near either angle. In such case it is not possible to obtain a skin flap with raw surface (the essential point in the operation) in the way previously described. The flap required is obtained by an incision up and in or out according to the angle affected. In suturing the internal angle in order to sustain the weight of the lid and prevent subsequent ectropion he makes use of a double armed suture passed with the loop of the thread in the thickness of the internal lateral ligament. Without reproducing the excellent diagrams that accompany the paper it is not possible to explain adequately the details of the technique which should be studied in the original.

E. E. H.

(5) Le Roux, Dr. H. (Caen).-Two cases of herpes of the cornea after antityphoid vaccination. (Deux observations d'herpès de la cornée consécutif à la vaccination antityphöidique.) Arch. d'Ophtal., Feb., 1921.

(5) Le Roux has had under his care two cases of this rare sequel to antityphoid vaccination. The first patient, a soldier of 28 years of age, had suffered from an attack of an eruption, presumably herpetic, on the right side of the face in 1914. In 1915 he had two injections of the vaccine at an interval of eight days without any special reaction. In 1916 he had another injection which was followed fifteen hours later by high fever. The following morning a herpetic eruption began near the mouth and spread 
upwards to the right fronto-temporal region and both ears. The next night the right eye became painful. A corneal ulcer developed and the lids were also affected. A fortnight later all injection had disappeared, but three days later there was a fresh outbreak on the face and the eye again became red. Recovery with normal vision took place at the end of six weeks.

The second patient was a soldier of 18 years of age, who was given three injections at intervals of one week. Three days after the last injection he had a marked general reaction, and his left eye was affected with typical herpes. He was discharged as convalescent a month later.

In both cases the corneal affection was of the dendritic type.

E. E. H.

(6) Koby, Dr. F. Ed.-Inferior uniocular hemianopia with retinal alterations visible specially with the red-free light. (Hémianopsie inférieure monoculaire avec altérations rétiniennes visibles surtout a la lumière anérythre.) Arch. d'Ophtal., June, 1921.

(6) Koby's patient was a man of 40 years, who complained of being unable to see more than half of an object with the left eye. He gave a history of sudden obscurations of vision dating back twenty years. The first of these attacks affected both eyes and was described as appearing like a veil. Later attacks had always been confined to the left eye. The last attack occurred a month before he came under observation, and had persisted. The field of vision of this eye was cut off inferiorly by a line almost exactly horizontal which missed the point of fixation. Vision of the left eye was 0.5 , and could not be improved. His general condition and history showed no cause for the hemianopia. Ophthalmoscopic examination : O.D. pale, particularly in the upper half. Superior arteries markedly contracted, some completely obliterated and surrounded by a white sheath. The central foveal reflex was absent. Red-free light showed loss of retinal fibre plan in upper half of retina. Koby discusses the aetiology of these arterial spasm cases and lays stress on the value of red-free light in determining the functional condition of the retina. A chart of the field of vision and a drawing of the fundus accompanies the paper.

E. E. H.

(7) St. Martin (Toulouse)--Acute unilateral retro-bulbar neuritis of dental origin. (Névrite rétro-bulbaire aiguë, unilatérale d'origine dentaire.) La Clin. Ophtal, June, 1921.

(7) St. Martin, after pointing out that many cases of retro-bulbar neuritis which have been attributed to dental disease are not sufficiently proved to have such an origin, reports a case of his 
own of a woman aged 27 years, in whom he considers that he excluded every other possible cause. The two premolars on the corresponding side were very carious, while pressure on the gum over their roots was painful. The teeth were extracted. At the root extremity of the second premolar there was a large infected cyst and a purulent alveolar cavity. Improvement in vision commenced within 48 hours, and at the end of three weeks vision was normal, while, on ophthalmoscopic examination, no trace could be found to indicate that anything had been wrong with the eye.

Ernest Thomson.

(8) Beauvieux, Dr., and Pesmé, Dr. P. (Bordeaux).-Tuberculous dacryo-adenitis ; attenuated tuberculosis of the lacrimal gland. (La dacryo-adénite tuberculeuse; tuberculose atténuée de la glande lacrimale.) Arch. d'Ophtal., Jan., 1922.

(8) Beauvieux and Pesmé describe a case of tumour of the lacrimal gland which they consider should be included in the group called attenuated tuberculosis of that structure by van Duyse in 1896. Their patient was a man of 41 years of age, in sound health and with an excellent personal and family history. The tumour, which occupied the position of the lacrimal gland, had grown very slowly and given rise to hardly any symptoms. It was very hard, mobile, and apparently encapsuled. On the supposition that it was of the nature of a fibroma it was decided to remove it after the failure of anti-syphilitic treatment to produce any alteration (there was no history of syphilis and the Wassermann reaction was negative). The tumour, which extended deeply into the orbit, was easily removed and healing proved uneventful. Microscopical examination showed a proliferation of dense fibrous connective tissue enclosing spaces which contained glandular acini, inter-acinous connective tissue and inflammatory cells of new formation. Some of these latter showed the more or less typical structure of tuberculous follicles with giant cells and lymphocytes. There was no trace of caseation. No tubercle bacilli were found, but injection of a part of the tissue into a guinea-pig gave rise to tuberculous peritonitis.

The authors discuss the differential diagnosis of tumours of the lacrimal gland and deal with the work of other observers.

They sum up their conclusions as follows :-

" 1 . Tuberculosis of the lacrimal gland is a very rare affection which may take one of two clinical forms :-

(a) The caseous form (exceptional).

(b) The sclerosing form, the one commonly observed.

2. It may occur in genuinely tuberculous individuals, or in 
young persons or adults apparently free from any tuberculous blemish.

3. The glandular infection is carried by the blood. It is, therefore, secondary either to a recognized lesion or to a deep focus that has not been identified.

4. It follows an attenuated and but slightly virulent course, and is characterized anatomically by an infiltration of perivascular and periacinous inflammatory cells with the presence of typical or atypical giant cells. Sclerosed fibrous tissue predominates, forming a barrier to infection and limiting it to small islands in the middle of which normal and destroyed acini appear. The absence of the bacillus of Koch is to be noted.

5. Attenuated tuberculosis of the lacrimal gland presents itself in the form of a hard tumour with slightly bossy surface, moveable, painless and capable of spontaneous retrogression. It may be uni- or bilateral.

6. Local prognosis is favourable on account of its structural peculiarities : general prognosis depends on the degree of tuberculization of the patient.

7. The affection may be confused with benign tumours of the lacrimal gland (adenoma, adeno-fibroma) and particularly with simple sclerosing hypertrophy (chronic dacryo-adenitis), which it resembles even histologically. The diagnosis can only be established by experimental inoculation "on the guinea-pig.

8. Treatment may be expectant on account of the possible spontaneous regression. The only rational treatment, however, is extirpation of the neoplasm."

E. E. H.

(9) Chaillous, M. J. (Paris).-Papilloedema and decompression. (Stase papillaire et craniectomie décompressive.) Bulletins et Mémoires de la Societé française d'Ophtalmologie, 1922.

(9) Chaillous pleads for earlier interference in cases of papilloedema, and gives a short series of six cases where decompression was of value in preserving sight. The risk of the operation is much increased if accompanied by opening of the dura. The important question is as to when interference should take place.

(1) If vision is normal or nearly so, operation may be postponed while energetic antispecific treatment is carried out.

(2) If treatment does not relieve headache or reduce papilloedema and vision is from $5 / 10$ to $6 / 10$, decompression should be resorted to without delay, and repeated a second time if necessary.

(3) In all cases where vision is reduced to $2-3 / 10$. Here, however, prognosis as regards preservation of sight is very guarded. If stasis does not disappear after craniectomy the dura should be opened. 
Three of his cases had a history extending over 6 to 9 years after operation. Full vision, or at any rate sufficiently good sight, was preserved for the patient to be enabled to exercise a profession.

\section{Charles Killick.}

(10) Koeller, H., and Hoffman, P. (Wuerzburg).-The influence of the vestibular apparatus on the innervation of the eye muscles. (Der Einfluss des Vestibularapparates auf die Innervation der Augenmuskeln.) Arch. f. Augenheilk., Vol. XC, Parts 2 and 3, 1922.

(10) Experiments were made upon rabbits to determine the effect of the vestibular " apparatus " on eye movements in rotation nystagmus, after-nystagmus, and when the labyrinth had been destroyed. The influence of the vestibular apparatus both in the waking and unconscious states shows itself by increasing or lessening the electric current variations of the " resting " tetanus of the muscles, according as the muscle under consideration is actually contracting or relaxing. On the other hand the frequency of the " resting" tetanus is not demonstrably influenced by it. There was no evidence of any special vestibular innervation mechanism of recognizable rhythm. The cutting out of vestibular innervation by destruction of both labyrinths did not do away with the currents of action of the muscles:

In the opinion of the authors of this paper it is unlikely that pairs of antagonistic muscles in the eye experience simultaneously any notable increase of their tone from the labyrinth.

JAMES Fison.

\section{BOOK NOTICES}

Optical Methods in Control and Research Laboratories. Vol. I, edition II, 1923. J. N. GoLdSMITH, S. JUDD LEWIS and F. Twyman. Adam Hilger, Ltd. 56 pages. Nine illustrations. Price, 1s. 6d.

The eye holds a unique position among the other organs of special sense, because of the accuracy with which it can effect certain kinds of comparison. It is for this reason that vision is made use of in almost all types of precise measurement. The ability of the eye to judge when two lines coincide caused the introduction of the vernier. The colorimeter and spectrophotometer were made possible because the eye can detect small inequalities of intensity and colour. New methods making use of the accuracy of 